\title{
Erratum to: Treatment costs of attention deficit hyperactivity disorder in Germany
}

\author{
Sebastian Braun ${ }^{1} \cdot$ Jan Zeidler $^{2} \cdot$ Roland Linder $^{3} \cdot$ Susanne Engel $^{3} \cdot$ \\ Frank Verheyen ${ }^{3} \cdot$ Wolfgang Greiner ${ }^{4}$
}

Published online: 17 February 2016

(c) Springer-Verlag Berlin Heidelberg 2016

\section{Erratum to: Eur J Health Econ (2013) 14:939-945 DOI 10.1007/s10198-012-0440-5}

In the original article, duplicates regarding the number of occupational therapy prescriptions and cost category occupational therapy were identified. Duplicates resulted in overestimation of the number of occupational therapy prescriptions and costs of occupational therapy. A corrected version of Tables 1, 2 and 4 as well as Fig. 1 presenting the key results of the analysis as well as corrected paragraphs are given below.

On Page 939, paragraph 3, second sentence in the abstract should read:

The total costs for these patients were $€ 2,412$, and the incremental costs were $€ 1,775$.

The online version of the original article can be found under doi:10.1007/s10198-012-0440-5.

Sebastian Braun

braun@herescon.com

1 Herescon GmbH-Health Economic Research and Consulting, Königsworther Straße 2, 30167 Hannover, Germany

2 Center for Health Economics, Leibniz University Hannover, Hannover, Germany

3 Scientific Institute of TK for Benefit and Efficiency in Health Care, Hamburg, Germany

4 Faculty of Health Sciences, University of Bielefeld, Bielefeld, Germany
On Page 939, paragraph 3, the third sentence in the abstract should read:

The largest proportions of incremental costs were due to outpatient care amounting to $€ 606$.

On Page 939, paragraph 4, second sentence in the abstract should read:

The expenses for outpatient and inpatient constitute the cost driver.

On Page 939, paragraph 4, third sentence in the abstract should read:

A relevant category regarding ADHD-treatment in Germany is occupational therapy.

On Page 941, paragraph 2, first sentence in the results should read:

In 2008, the mean overall direct costs amounted to $€ 2,412$ (see Table 1).

On Page 941, paragraph 2, second sentence in the results should read:

Outpatient care accounted for the largest proportion of the total costs with an amount of $€ 837$ (35\%).

On Page 941, paragraph 2, third sentence in the results should read:

However, the costs for hospital treatment (32\%), medication $(20 \%)$ and therapeutic devices and remedies (10\%) were relevant.

On Page 941, paragraph 3, third sentence in the results should read:

In 2008, these incremental costs added up to $€ 1,775$ on average per patient in all cost categories (Table 2).

On Page 941, paragraph 3, fourth sentence in the results should read: 
Table 1 Total costs in 2008 in $€(n=30,264)$

\begin{tabular}{lrccr}
\hline Type of costs & Mean & Standard deviation & Minimum & Maximum \\
\hline Outpatient care & 837 & 764 & 0 & 38,509 \\
Inpatient care & 779 & 4,066 & 0 & 190,393 \\
Pharmaceuticals & 483 & 1,392 & 0 & 47,846 \\
Therapeutic devices and remedies & 228 & 601 & 0 & 32,034 \\
Sick leave payments & 50 & 976 & 0 & 53,658 \\
Rehabilitation & 35 & 584 & 0 & 49,096 \\
Total & 2,412 & 4,933 & 19 & 214,353 \\
\hline
\end{tabular}

Table 2 Incremental costs in 2008 in $€(n=30,264)$ $n=151,320$ )

\begin{tabular}{lccc}
\hline Type of costs & $\begin{array}{l}\text { Mean } \\
\text { ADHD patients }\end{array}$ & $\begin{array}{l}\text { Mean } \\
\text { Control group }\end{array}$ & Incremental costs \\
\hline Outpatient care & 837 & 231 & 606 \\
Inpatient care & 779 & 178 & 601 \\
Pharmaceuticals & 483 & 123 & 359 \\
Therapeutic devices and remedies & 228 & 84 & 144 \\
Sick leave payments & 50 & 11 & 39 \\
Rehabilitation & 35 & 9 & 26 \\
Total & 2,412 & 637 & 1,775 \\
\hline
\end{tabular}

Table 4 Overview of the average costs 2008 (standard deviation) of all age groups in $€$

\begin{tabular}{|c|c|c|c|c|c|c|}
\hline \multirow[t]{2}{*}{ Type of costs } & \multicolumn{2}{|l|}{$0-5$ years } & \multicolumn{2}{|l|}{$6-17$ years } & \multicolumn{2}{|l|}{$18-90$ years } \\
\hline & $\begin{array}{l}\text { ADHD } \\
(n=552)\end{array}$ & $\begin{array}{l}\text { Control group } \\
(n=2,760)\end{array}$ & $\begin{array}{l}\text { ADHD } \\
(n=24,268)\end{array}$ & $\begin{array}{l}\text { Control group } \\
(n=121,340)\end{array}$ & $\begin{array}{l}\text { ADHD } \\
(n=5,444)\end{array}$ & $\begin{array}{l}\text { Control group } \\
(n=27,220)\end{array}$ \\
\hline Outpatient care & $866(684)$ & $320(341)$ & $841(757)$ & $213(340)$ & $819(801)$ & $301(510)$ \\
\hline Inpatient care & $567(1,993)$ & $190(1,896)$ & $690(3,970)$ & $142(1,817)$ & $1,198(4,587)$ & $335(2,365)$ \\
\hline Pharmaceuticals & $147(288)$ & $71(285)$ & $465(1,295)$ & $111(6,651)$ & $595(1,806)$ & $182(1,499)$ \\
\hline $\begin{array}{l}\text { Therapeutic devices } \\
\text { and remedies }\end{array}$ & $539(700)$ & $144(540)$ & $234(584)$ & $85(568)$ & $173(650)$ & $80(473)$ \\
\hline Sick leave payments & $0(0)$ & $0(0)$ & $0(2)$ & $0(2)$ & $277(2,289)$ & $61(948)$ \\
\hline Rehabilitation & $31(366)$ & $9(252)$ & $30(530)$ & $7(312)$ & $61(794)$ & $19(409)$ \\
\hline Total & $2,150(2,627)$ & $734(2,346)$ & $2,260(4,568)$ & $558(7,579)$ & $3,123(6,401)$ & $978(3,818)$ \\
\hline
\end{tabular}

The costs for outpatient care accounted for the largest proportion of $€ 606$.

On Page 941, paragraph 3, fourth sentence in the results, the sentence "Of these costs, $€ 971$ were for occupational therapy" should be deleted.

On Page 942, paragraph 8, first sentence in the results should read:

The group of patients with an age of 18 years and older differed from the basic analysis in relation to mean total costs.

On Page 942, paragraph 8, second sentence in the results should read:

The costs in the ADHD group and the control group $(€ 3,123$ vs. €978) as well as the ADHD-specific costs
$(€ 2,145)$, respectively, were slightly higher than in the other groups.

On Page 942, paragraph 9, second sentence in the results should read:

Outpatient care and inpatient care constituted the largest cost factor in absolute terms and as ADHD-specific costs.

On Page 942, paragraph 9, third sentence in the results should read:

Expenses in the service sector therapeutic devices and remedies were considerably lower within the older age groups.

On Page 942, paragraph 10, first sentence in the results should read: 


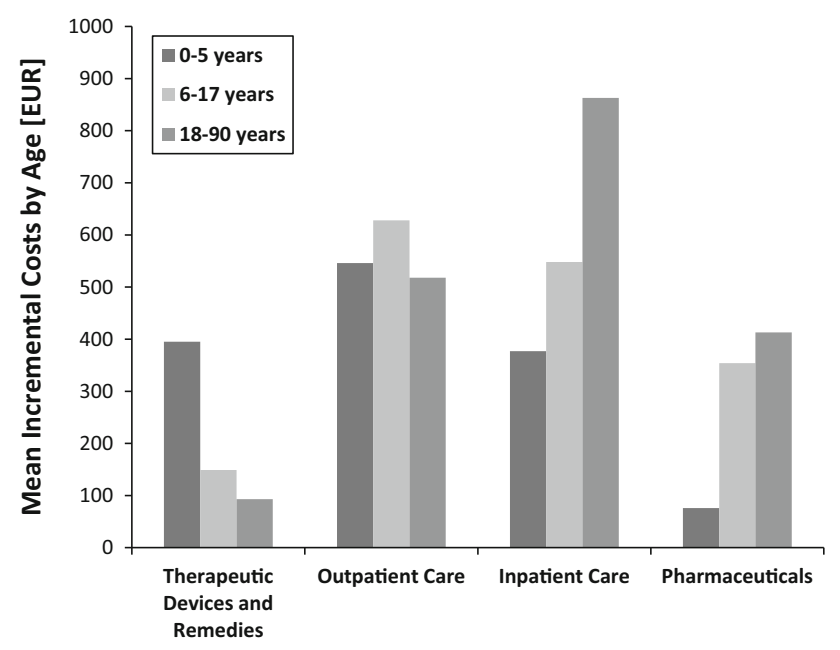

Fig. 1 Mean incremental costs in different age groups and types of costs

In the group of newborn to 5-year-old patients expenses for therapeutic devices and remedies ranked third after inpatient and outpatient treatment. However, in the age group of 6-17 years and 18-90 years next to inpatient and outpatient treatments, medication expenses ranked third.

On Page 943, paragraph 1, fifth sentence in discussion should read:

However, these findings did not include cost categories such as therapeutic devices and remedies which were not available in the data set.

On Page 943, paragraph 2, second sentence in discussion should read:

The expenses for outpatient care and inpatient care constitute the cost driver.

On Page 943, paragraph 4, first sentence in discussion should read:

A relevant category regarding ADHD-treatment in Germany is therapeutic devices and remedies. 